\title{
Introduction to the mini symposium on innovative technologies and quality in medicine in the time of a pandemic
}

\author{
Christine C. Huttin ${ }^{a, b}$ \\ ${ }^{a}$ Business and Economics of HealthCare, University Aix Marseille, Marseille, France \\ E-mail: christine.huttin@iae-aix.com \\ ${ }^{\mathrm{b}}$ CEO, Endepusresearch, Inc., Cambridge, MA, USA \\ E-mail: chxyinfo@endepusresearchinc.com
}

Professor Christine C Huttin was invited in June 2021 to co-organize an event entitled "Quality in medicine, global health and law, in the time of a pandemic". This collaboration started in 2018 for a series of annual roundtables on quality, with the Polish Academy of Sciences Sciences (PAS) Scientific Center in Paris (France) and Dr Margaret Chalupowski (MD, PhD). A brief history on the collaboration with the PAS Scientific Center in Paris can be found in the Appendix. A first mini symposium on quality in medicine was published in Technology and Health Care in 2018. This issue includes a second mini symposium on quality of medicine, from the 2021 PAS event (paris.pan.pl/en). It is a selection of four papers on innovative technologies and responses in the time of a pandemic, to ensure quality.

Dr. Valérie Pimpaneau and Dr. Emmanuelle Voisin highlight the innovative response of the biopharma industry in the context of the COVID-19 pandemic, especially with an adapted approval process, adapted regulatory environment, guidelines and analytical development strategy.

Dr. Rosa Delgado analyzes the transition to IPv6 and its implication for the transformation of health care, with the boost of digitalization under the pandemic.

Dr. Jeannine Lemaire, Dr. Elsa Ramil, Dr. Véronique I Thouvenot and Dr. Pons J Serrano present the launch of an intelligent platform called Epidemix: an innovative ecosystem of digital tools centralizing official and validated information, to accelerate science on COVID-19 and propose sets of solutions.

Professor Christine Huttin provides a contribution on the economics of mRNA technology platforms and the importance of tool companies in the biotech development chain for quality assurance of such technologies. She highlights some research areas for academic collaboration.

\section{Appendix: A brief history on the collaboration with the PAS Scientific Center in Paris. Written by Margaret Chalupowski, MD, PhD}

The goal of the annual conferences on quality in medicine, global health and law held at the PAS Scientific Center in Paris, is to facilitate productive collaboration among healthcare organizations and academic centers in Poland, France, as well as other countries around the globe. 
After a productive and inspiring roundtable meeting on quality improvement in medicine held at the PAS Scientific Center in Paris in April 2018, the second PAS conference was held on May 15 and 16, 2019, and was focused on the role of international collaboration in improving quality of care. The third PAS conference was held in Paris on June 14-16, 2021 and aimed to explore the role of interprofessional collaboration in addressing the scientific, ethical, legal, social and managerial challenges emerging in the midst of an unprecedented global epidemiological crisis going on since the beginning of 2020.

The conference was designed to capture an instantaneous snapshot of the current situation as seen by a multidisciplinary ensemble of professionals representing a variety of backgrounds, cultures, countries, and points of view. Three keynote speakers set the stage by presenting the essence of the pandemic from the global, French and Polish perspective. Five roundtable discussions gave the audience an understanding of how the pandemic changed the policies and research priorities of leading global and regional organizations confronting the biggest challenge of our times.

Finally, ten interactive panels were designed to provide information and inspiration from professionals other than frontline medical scientists and frontline healthcare workers. The panelists were asked to give short presentations describing the essence of their professional endeavors and lessons learned in the midst of the geo-political and epidemiological tsunami. The common baseline framework of the discussions was anchored in the concept of quality of care defined as the degree to which the services provided to individual patients and entire populations are in compliance with four specific criteria: current scientific knowledge, professional ethical standards, applicable law, and principles of fairness and equity. The ultimate goal of the meeting was the promotion of the scientific, academic, clinical and organizational excellence in addressing the essence of the current epidemiological crisis, with a specific emphasis on the role of innovative technologies in improving the quality of care. 